Disponível em

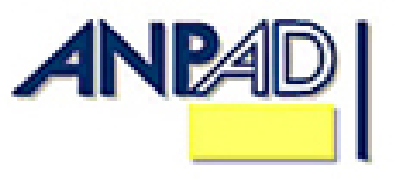

http://www.anpad.org.br/rac

RAC, Rio de Janeiro, v. 16, n. 2, art. 2,

pp. 200-216, Mar./Abr. 2012

$(\mathrm{co})$ EY-No

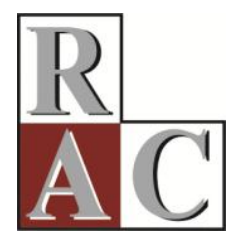

\title{
Sentidos do Trabalho e Racionalidades Instrumental e Substantiva: Interfaces entre a Administração e a Psicologia
}

\section{Meanings of Work and Instrumental and Substantive Rationality: Interfaces between Management and Psychology}

Sílvia Patricia Cavalheiro de Andrade*

E-mail: silviapcandrade@yahoo.com.br Universidade Federal de Santa Catarina - UFSC

Florianópolis, SC, Brasil.

Suzana da Rosa Tolfo

E-mail: srtolfo@yahoo.com.br

Universidade Federal de Santa Catarina - UFSC

Florianópolis, SC, Brasil.

Eloise Helena Livramento Dellagnelo

E-mail: eloise@cse.ufsc.br

Universidade Federal de Santa Catarina - UFSC

Florianópolis, SC, Brasil.

* Endereço: Sílvia Patricia Cavalheiro de Andrade

Rua Rui Barbosa, 327, apto. 102, Bloco 02, Edif. Condessa, Agronômica, Florianópolis/SC, 88025-301.

Copyright (C) 2012 RAC. Todos os direitos, até mesmo de tradução, são reservados. É permitido citar parte de artigos sem autorização prévia, desde que seja identificada a fonte. 


\title{
Resumo
}

Os debates sobre racionalidade e seus conceitos são clássicos em administração. Em contrapartida, os estudos sobre os significados e os sentidos atribuídos ao trabalho, na psicologia, são da década de 1970. Ao estudar os sentidos do trabalho, os autores não têm se remetido à questão das racionalidades instrumental e substantiva, mas priorizado a identificação daquilo que caracteriza um trabalho com sentido. Neste ensaio teórico, tem-se como pressuposto que os sentidos atribuídos ao trabalho estão relacionados aos tipos de racionalidades presentes na sociedade e nas organizações de trabalho. Pretende-se, assim, identificar aproximações entre os traços que caracterizam os sentidos atribuídos ao trabalho e as racionalidades instrumental e substantiva. Apresentam-se elementos que caracterizam os sentidos do trabalho com base em referências da psicologia, enfocando as pesquisas de Morin (1996, 2001), bem como estudos que caracterizam os traços constitutivos das racionalidades em questão, tradicionalmente estudados na administração, com ênfase em Serva (1993, 1996, 1997a, 1997b). Essa tentativa de articulação possibilitou também o desenvolvimento da concepção de sentidos do trabalho do tipo instrumental e do trabalho do tipo substantivo; destacando-se que há uma imbricação entre ambos os tipos de sentidos nas organizações.

Palavras-chave: sentidos do trabalho; racionalidade instrumental; racionalidade substantiva; sentido instrumental; sentido substantivo.

\begin{abstract}
The debates about rationality and its concepts are classical in management studies. Nevertheless, research on the meanings attributed to work, from psychology, are from the 1970s. When studying the meanings of work, authors have not referred to the issue of instrumental and substantive rationality, but have prioritized the identification of that which characterizes work with meaning/sense. In this theoretical essay, the presumption is that the meanings attributed to work are related to the types of rationality present in society and work organizations. As such, the aim is to identify approximations between the features that characterize the meanings attributed to work and instrumental and substantive rationality. Elements that describe the meanings of work are presented, based on psychological references and focusing on research by Morin $(1996,2001)$; as well as studies that characterize the constitutive features of instrumental and substantive rationality, traditionally studied in management, with emphasis on Serva (1993, 1996, 1997a, 1997b). This possible articulation allowed for the development of work meaning/sense conception of the instrumental type and work meaning/sense of the substantive type; highlighting that there is an overlap between both types of senses in organizations.
\end{abstract}

Key words: meanings of work; instrumental rationality; substantive rationality; instrumental sense; substantive sense. 


\section{Introdução}

Os fenômenos significados e sentidos do trabalho são multifacetados, constituídos de diversas variáveis pessoais e sociais, as quais são investigadas por autores de diferentes áreas e em diferentes países (Basso, 1998; Bendassolli, 2009; Borges, 1997; Meaning of work international research team [MOW], 1987 ${ }^{(1)}$; Morin, 1996, 2001; Oliveira, Piccinini, Fontoura, \& Schweig, 2004; Tolfo, Coutinho, Almeida, Baasch, \& Cugnier, 2011). A maioria desses pesquisadores tem como foco o estudo de significados e sentidos atribuídos ao trabalho por profissionais como engenheiros químicos, trabalhadores temporários, da construção civil, do comércio, professores, administradores e outros. Os pesquisadores do grupo MOW enfatizam que ainda há muitas lacunas a serem preenchidas nos estudos sobre a temática, pois novas variáveis precisam ser exploradas. Com isso, desenvolver pesquisas com variáveis ainda não investigadas e interfaces com diferentes áreas contribui para ampliar o conhecimento e as intervenções relacionadas aos fenômenos, bem como para aperfeiçoar os estudos sobre o tema.

Avalia-se que, ao estudar os significados e sentidos do trabalho, os pesquisadores têm privilegiado a análise de diferentes categorias profissionais, e não têm se remetido à questão da racionalidade, a qual representa um elemento fundamental na dinâmica das organizações de trabalho. Kalberg (1980) destaca que, segundo o pensamento weberiano, as diferentes formas organizacionais encontradas na realidade social podem ser explicadas pela predominância do uso de tipos específicos de racionalidades.

Neste ensaio teórico, tem-se como pressuposto que os sentidos atribuídos ao trabalho podem estar relacionados aos tipos de racionalidades presentes na sociedade e nas organizações. Busca-se, assim, estabelecer uma aproximação entre os elementos que caracterizam os sentidos do trabalho com base na psicologia e os traços constitutivos das racionalidades instrumental e substantiva, conforme tradicionalmente estudados na administração, enfatizando que há uma presença concomitante de dois tipos de sentidos atribuídos ao trabalho no ambiente organizacional. Destaca-se que, por um lado, a racionalidade instrumental está pautada no cálculo utilitário ${ }^{(2)}$ das consequências, na busca do êxito econômico e do poder, ou seja, supõe-se que as ações das pessoas sejam direcionadas, basicamente, por incentivos econômicos, motivos utilitaristas, pelo alcance de maior ganho financeiro e de poder. Já na racionalidade substantiva, a ação é direcionada para autorrealização, satisfação, julgamento ético, autenticidade, autonomia e valores emancipatórios, como solidariedade, liberdade e bem-estar coletivo (Serva, 1996, 1997a, 1997b). O autor explica que, nas práticas das organizações, estão presentes tanto a razão substantiva quanto a razão instrumental, pois não há uma organização regida por apenas uma delas.

Primeiramente, disserta-se, neste artigo, sobre os conceitos de significados e sentidos do trabalho e são apresentados alguns estudos sobre os fenômenos. Na sequência, caracterizam-se duas categorias fundamentais da dinâmica organizacional, as racionalidades instrumental e substantiva. Estas, com base na análise da literatura de autores clássicos e de pesquisadores contemporâneos (A. G. Ramos, 1989; Clegg, 1990; Dellagnelo \& Machado-da-Silva, 2000; Kalberg, 1980; Serva, 1993, 1996, 1997a, 1997b; Weber, 1994), são caracterizadas por traços que possibilitam aproximações com os elementos constitutivos dos significados e sentidos do trabalho investigados na psicologia (Bendassolli, 2009; Borges, 1997; Hackman \& Oldham, 1975; Morin, 1996, 2001; MOW, 1987; Tolfo et al., 2011). Destaca-se que a análise dos sentidos do trabalho é feita aqui com enfoque em Morin (1996, 2001), pois a proposta de investigação da autora é, em geral, a mais utilizada nos estudos brasileiros sobre o fenômeno nas Ciências da Administração (Alberton, 2008; Betiol, 2006; Morin, Tonelli, \& Pliopas, 2003, 2007; Oliveira, 2004; Oliveira et al., 2004; Ono \& Binder, 2010; Ribeiro, 2007). Já as racionalidades instrumental e substantiva são analisadas com ênfase em Serva (1993, 1996, 1997a, 1997b), pois os estudos do autor são usados como referências em diversas pesquisas brasileiras sobre o assunto na administração (M. F. Ramos 2006; Pinto, 2001; Severo \& Pedrozo, 2008; Valeriano, 2006). Assim, em seguida, aborda-se a articulação entre os sentidos do trabalho e a racionalidade; e finaliza-se destacando algumas reflexões sobre a temática. 


\section{Sentidos e Significados do Trabalho}

Identifica-se, na literatura, um desenvolvimento crescente de pesquisas sobre os fenômenos significados e sentidos do trabalho (Alberton, 2008; Basso, 1998; Bendassolli, 2009; Betiol, 2006; Borges, 1997; Morin, 1996, 2001; MOW, 1987; Oliveira et al., 2004; Ono \& Binder, 2010; Ribeiro, 2007; Tolfo \& Piccinini, 2007), por meio das quais se busca aperfeiçoar e aprofundar as descobertas científicas nessa área. Esses fenômenos têm sido pesquisados com maior ênfase a partir de 1970. Entre as principais correntes epistemológicas que dão suporte aos estudos sobre o tema na psicologia, há: a sócio-histórica ou histórico-crítica, a humanista-fenomenológica, a construcionista, a cognitivista, e os estudos culturais. Algumas dessas perspectivas teóricas têm como objeto de estudo a produção de sentidos e significados na vida cotidiana, e, outras, de sentidos e significados atribuídos ao trabalho.

Há estudiosos como os do grupo MOW (1987), que utilizam o conceito de significados do trabalho; outros, como Morin $(1996,2001)$, que adotam o termo sentidos do trabalho. A autora apresenta a significação como um dos componentes constituintes dos sentidos (Morin, 1996). Borges (1997, 1998) trata os sentidos e os significados como elementos do mesmo construto, os quais apresentam caráter de complementaridade. Enfatiza-se que os estudiosos do grupo MOW (1987), de Morin $(1996,2001)$ e Borges $(1997,1998)$ não abordam em seus trabalhos a diferenciação etimológica dos termos sentidos e significados. Já para Hackman e Oldham (1975) e Basso (1998), estes são construtos diferentes. $\mathrm{O}$ fato de ora os termos significados e sentidos serem apresentados como sinônimos, ora como construtos diferentes, pode dificultar a evolução de estudos sobre a temática, tornando-se necessária uma melhor definição dos conceitos (Tolfo et al., 2011; Tolfo \& Piccinini, 2007). Assim, embora exista interdependência entre os termos, os significados do trabalho podem ser entendidos como construídos coletivamente em determinado contexto histórico, econômico e social, e os sentidos são caracterizados por ser uma produção pessoal em função da apreensão individual dos significados coletivos, a partir de experiências concretas (Tolfo et al., 2011). Basso (1998) evidencia, com base nos estudos de Leontiev (1978), que significado é a generalização e a fixação da prática social humana representada por instrumentos, técnicas, linguagem e relações sociais; e sentido é a razão, o motivo que incita a pessoa a realizar seu trabalho.

Historicamente, os primeiros estudos empíricos apresentados sobre significados e sentidos atribuídos ao trabalho foram realizados por Hackman e Oldham (1975). Os autores relacionaram a qualidade de vida no trabalho e o significado deste, e concluíram que um trabalho com significado possui três características essenciais: (a) variedade de tarefas - grau em que a função requer uma variedade de competências para desenvolver o trabalho; (b) trabalho não alienante - visão não fragmentada do processo, o qual possui finalidade, valor, possibilita autonomia, liberdade e independência para determinar a forma como as tarefas serão realizadas; e (c) significado da tarefa grau em que a tarefa tem um impacto substancial na vida de outras pessoas, tanto na organização quanto na sociedade em geral.

Os estudiosos que mais contribuíram para o desenvolvimento dos estudos sobre o fenômeno fazem parte do grupo MOW (1987). Estes utilizam o termo significados do trabalho, o qual é representado pelo significado individual, coletivo/grupal e social atribuído a ele; pela utilidade do trabalho para a organização; autorrealização e satisfação geradas pela realização do trabalho; pelo sentimento de desenvolvimento e evolução pessoal e profissional; e pela liberdade e autonomia existentes para a execução do trabalho. Os estudos pioneiros sobre a temática foram desenvolvidos pelo grupo entre 1981 e 1983 em oito países (Bélgica, Inglaterra, Alemanha, Israel, Japão, Holanda, Estados Unidos e ex-Iugoslávia) e, junto a 14.700 profissionais, em sua maioria do setor privado. Foram investigadas, por meio de questionários, variáveis que explicam os significados que esses indivíduos atribuíam ao trabalho. Os pesquisadores definiram três variáveis principais de análise: (a) centralidade do trabalho - representa os graus de importância absoluta e relativa do trabalho em determinado momento da vida. A centralidade absoluta refere-se à importância dada ao trabalho em termos globais e absolutos (exemplo: é a atividade mais importante na vida do indivíduo ou é a menos importante), e a centralidade relativa diz respeito à importância concedida ao trabalho em comparação 
à importância dada a outras esferas relevantes da vida (aqui se supõe uma hierarquização das esferas da vida); (b) normas sociais sobre o trabalho - as quais se referem às recompensas, direitos e deveres relacionados a ele; e (c) resultados valorizados do trabalho - os quais revelam os motivos que levam uma pessoa a trabalhar. Ruiz-Quintanilla e Claes (2000) explicam que a análise dessa variável permite identificar duas dimensões de motivos que levam uma pessoa a trabalhar. Uma delas é caracterizada pela busca de objetivos econômicos, como a remuneração e a segurança no trabalho, ou seja, uma orientação instrumental para o trabalho. A outra dimensão é denominada de objetivos expressivos, os quais são representados pela autonomia, realização de um trabalho interessante e possibilidade de aplicação das competências. As considerações feitas por Ruiz-Quintanilha e Claes (2000) sobre os motivos que levam as pessoas a trabalhar, são identificadas também nos estudos de Kaplan e Tausky (1974 como citado em Bendassolli, 2009) sobre orientações utilitárias e expressivas para o trabalho. Na função expressiva do trabalho, ele é considerado uma atividade intrinsecamente satisfatória, possibilita posição e prestígio social, é moralmente aceitável e fonte de experiências e relacionamentos humanos satisfatórios. Já para a função utilitária, é considerado uma atividade econômica, um meio de ganhar a vida, e uma atividade programada, rotineira, que mantém o indivíduo ocupado. Na mesma direção, Morin (1996) também identifica que o trabalho preenche duas funções na vida, uma função utilitária e uma função expressiva.

Hoje, é especialmente a primeira que chama a atenção dos gerentes e funcionários, desvalorizando assim a segunda. No entanto, deve-se estar ciente da importância das funções expressivas do trabalho sobre as atitudes, comportamentos e saúde mental dos indivíduos. Se o corpo precisa de alimento para viver com saúde, o espírito humano também precisa de seu alimento. O ser humano precisa expressar sua criatividade e transcender-se para se valorizar. Os gestores devem revalorizar as funções expressivas do trabalho, através de incentivos e recompensando de modo justo os esforços de criatividade, de serviços aos outros e o empenho pessoal (Morin, 1996, p. 281).

Os pesquisadores do MOW (1987) investigaram, também, as diferentes definições do trabalho. Com base em estudos empíricos, os estudiosos que fazem parte dessa equipe identificaram seis padrões de definição do trabalho, os quais se classificam de A a F. Para os padrões de A a C, o trabalho assume uma concepção positiva. Em relação ao padrão A, acrescenta valor a qualquer coisa, deve-se prestar conta do mesmo, recebe-se dinheiro para realizá-lo; no padrão B, ao realizar-se o trabalho existe um sentimento de vinculação, recebe-se dinheiro para realizá-lo, faz-se isso para contribuir com a sociedade. No padrão C, por sua vez, outros se beneficiam de seu trabalho, recebe-se dinheiro para realizá-lo, faz-se o trabalho para contribuir com a sociedade, ele é fisicamente exigente.

Nos padrões D e E, o trabalho assume uma concepção negativa. No padrão D, recebe-se dinheiro para realizar o trabalho, faz parte de suas tarefas, alguém lhe diz o que fazer, não é agradável. Para o padrão E, o trabalho é mentalmente e fisicamente exigente, recebe-se dinheiro para fazê-lo, mas não é agradável.

Por fim, em relação ao padrão F, o qual representa uma concepção neutra do trabalho, existe um horário regular para desenvolvê-lo, recebe-se dinheiro para fazê-lo, faz parte de suas tarefas. Os resultados dos estudos revelaram que, para $55,8 \%$ dos sujeitos participantes, a concepção positiva do trabalho prevaleceu na maioria dos países investigados como Japão, Bélgica, Inglaterra, Israel, Holanda e ex-Iugoslávia, sendo maior entre os japoneses; e, entre alemães e americanos, predominou uma concepção neutra $(11,8 \%$ dos sujeitos) do trabalho. A concepção negativa do trabalho predominou para $32,3 \%$ da amostra investigada.

Constatou-se ainda que o trabalho possa assumir desde uma condição neutra até de centralidade na identidade pessoal e social dos investigados. O mesmo encontra-se, na maioria dos países pesquisados, exceto no Japão e na ex-Iugoslávia, em segundo lugar em termos de importância; em primeiro lugar está a família e, em terceiro, o lazer. Os pesquisadores verificaram, também, que, em todos os padrões, o salário representa um elemento importante na definição de trabalho. Isto pode revelar que, para a maioria dos indivíduos investigados, existem poucas diferenças entre trabalho e emprego, visto que este, segundo Jahoda (1987), corresponde a uma forma específica de trabalho 
econômico, o qual pressupõe uma remuneração e é regulado por um acordo contratual de caráter jurídico.

Uma das principais estudiosas brasileiras sobre o assunto, Borges (1997), a qual trabalha predominantemente com a perspectiva cognitivista, utiliza os conceitos e as definições de significado do trabalho com base no grupo MOW (1987). Para ela, o significado do trabalho é construído no processo de socialização, no qual os indivíduos se apropriam de conteúdos referentes às ideologias do mesmo, "aos aspectos que compõem a estrutura social das organizações" e aos aspectos socioeconômicos das ocupações e do ramo de atividade (Borges, Tamayo, \& Alves, 2005, p. 164). Evidencia-se, aqui, que a racionalidade, ao representar uma categoria fundamental na dinâmica organizacional, está imbricada nos significados atribuídos ao trabalho. A autora buscou aprofundar, junto a uma amostra de trabalhadores da construção habitacional e do comércio no Distrito Federal e em Natal, a análise acerca da estrutura fatorial das crenças sobre o trabalho por meio de um inventário denominado de Inventário do Significado do Trabalho (IST). Foram investigadas quatro facetas que constituem o significado do trabalho: a centralidade do trabalho, os atributos valorativos, os atributos descritivos, e a hierarquia dos atributos. A centralidade do trabalho consiste no grau de importância atribuída a ele em comparação com as demais esferas da vida. Os atributos valorativos e descritivos, por sua vez, correspondem a uma nova formulação teórica, na qual os valorativos dizem respeito a como o trabalho deve ser, e os descritivos definem como ele é realmente. Os atributos valorativos são representados pelos seguintes fatores: independência financeira e prazer, justiça no trabalho, esforço físico, aprendizagem e dignidade social. Os atributos descritivos são formados por estes fatores: expressão e independência financeira, respeito, execução e função social. A hierarquia dos atributos refere-se à organização dos valorativos e descritivos segundo uma ordem de importância, ou seja, uma classificação ordenada ao longo de um continuum (Borges, 1997).

Os estudos de Morin $(1996,2001)$ também são fortemente influenciados pelas pesquisas desenvolvidas pelos estudiosos do grupo MOW (1987) e pelos psiquiatras da linha existencialista, Viktor Frankl e Irvin Yalom. Frankl (1991, p. 100) defende que a vida das pessoas precisa ter sentido, e que uma das formas de se descobrir sentido na vida é "criando um trabalho ou praticando um ato". Morin (1996, p. 269) busca investigar em suas pesquisas as características de um trabalho que tenha sentido $^{(3)}$ e argumenta que "o sentido é um efeito, um produto da atividade humana.... o sentido é uma estrutura afetiva formada por três componentes: a significação, a orientação e a coerência". A significação diz respeito à forma que o indivíduo apreende, compreende e define o trabalho, bem como o valor ou a importância que aquele atribui a este. Já a orientação envolve um propósito, uma intenção, um objetivo pessoal que guia as ações da pessoa. A coerência, por fim, é a harmonia ou o equilíbrio que alguém espera entre sua vida interior e sua vida em sociedade, a qual ocorre por meio de atos de engajamento orientados por um propósito transcendental. A proposta de investigação sobre os sentidos do trabalho apresentada pela autora embasou a construção deste artigo, pois, em geral, ela é utilizada nos estudos brasileiros sobre o fenômeno nas Ciências da Administração. Além disso, ao analisar as dimensões de análise utilizadas em suas investigações (Morin et al., 2003, 2007) - dimensão individual (satisfação pessoal, independência e sobrevivência, crescimento e aprendizagem, identidade); organizacional (utilidade, relacionamentos); e social (o sentimento de executar um trabalho que contribua para a sociedade, inserção social) - infere-se que estas apresentam alguns traços semelhantes aos elementos constitutivos de uma racionalidade instrumental e substantiva. Bendassolli (2009), por sua vez, enfatiza que os estudos da autora estão entre as perspectivas emergentes de investigação dos sentidos do trabalho, inclusive no contexto brasileiro.

Nos estudos realizados em Quebec e na França, Morin (2001) buscou, por meio de um questionário construído a partir do utilizado pelo MOW (1987) e de entrevistas, ambos aplicados a estudantes de administração e a administradores, caracterizar o fenômeno trabalho e identificar os sentidos que os indivíduos atribuem a ele. Verificou-se que os participantes da pesquisa possuem, predominantemente, uma concepção positiva do trabalho e que um trabalho com sentido possibilita independência - obtida por meio do salário -, autonomia, autodesenvolvimento, relacionamentos satisfatórios, aprendizagem e crescimento, e contribui para a sociedade. Nas pesquisas aplicadas por Morin, Tonelli e Pliopas (2003, 2007), em alunos de um curso de especialização em administração de 
uma instituição de ensino superior na cidade de São Paulo, o sentido do trabalho foi investigado por meio da análise das três dimensões anteriormente citadas (individual, organizacional e social). As autoras enfatizam que

O primeiro aspecto a ser ressaltado para os participantes dos seus estudos é o sentido positivo dado pelos entrevistados ao trabalho ... os entrevistados se enquadram no padrão B da pesquisa do grupo Mow (1987), .... Não há entre os respondentes alguém que apresente padrões negativos ou neutros (Morin et al., 2007, p. 54, grifo nosso).

Verifica-se que as autoras utilizam os padrões de concepção do trabalho apresentados pela equipe MOW (1987) para caracterizar um trabalho com sentido positivo. Ou seja, conforme o conceito exposto no padrão $\mathrm{B}$, ao realizar o trabalho existe um sentimento de vinculação, recebe-se dinheiro para realizá-lo, faz-se isso para contribuir com a sociedade.

Ribas (2003) evidencia que, além do trabalho representar fonte de autorrealização e satisfação, este pode assumir, ainda, uma concepção negativa, sendo caracterizado como maldição, castigo, coerção, esforço e penalidade. Esta condição negativa pode ser evidenciada no estudo de Betiol (2006, p. 15). A autora baseou-se na proposta de investigação dos sentidos do trabalho apresentada por Morin (1996, 2001), e pesquisou, por meio da aplicação de questionários, 800 sujeitos de uma empresa pública de serviços na região parisiense, e 400 sujeitos de uma empresa pública de serviços localizada na região metropolitana de São Paulo. Constatou-se que o trabalho "ainda é obrigação e constrangimento" (Betiol, 2006, p. 15). E que, para ter sentido, "deve respeitar os valores humanos e ser fonte de aprendizagem e inserção social" (p. 15).

As pesquisas realizadas pelo grupo MOW (1987) e por Morin (2001) demonstram que a maioria das pessoas, mesmo que tivesse condições para viver o resto da vida confortavelmente, continuaria a trabalhar. Acreditam que, trabalhando, relacionam-se com outras pessoas, têm um sentimento de vinculação, sentem que têm algo para fazer, evitam o tédio e têm um objetivo na vida (Morin, 2001). Essas constatações são identificadas também no estudo pioneiro de Morse e Weiss (1955) sobre resultados esperados por meio do trabalho, no qual os autores defendem que restringir a noção deste a um simples meio de ganhar a vida é um grande equívoco.

Avalia-se que existem divergências em torno dos fenômenos significados e sentidos do trabalho devido à imprecisão conceitual dos construtos sentidos e significados, e por tratar-se de fenômenos multifacetados constituídos de diversas variáveis pessoais e sociais, investigadas por autores de diferentes perspectivas teóricas. Com isso, aprofundar o estudo desses fenômenos, em interface com outras áreas contribui para aperfeiçoar os estudos sobre a temática. Betiol (2006) explica que investigar os sentidos do trabalho, seus impactos, as relações que se estabelecem entre trabalhadores e destes com as organizações em que atuam representa um desafio para as áreas de interesse desse fenômeno devido ao caráter multifacetado do mesmo.

Evidencia-se, ainda, segundo Morin (2001), que conhecer as características que um trabalho deve apresentar a fim de ter sentido para aqueles que o realizam pode orientar as decisões e as intervenções dos responsáveis pelos processos de transformação organizacionais. Além disso, pode representar uma oportunidade para obter melhor qualidade de vida no trabalho, bem como eficácia organizacional. A autora argumenta que se deve expandir o conceito de eficácia organizacional, o qual precisa implicar, além dos valores econômicos, também valores sociais, morais, espirituais e/ou ecológicos. Verifica-se, assim, uma possível articulação entre os elementos que caracterizam os sentidos do trabalho e os traços constitutivos das racionalidades instrumental e substantiva.

\section{Racionalidades Instrumental e Substantiva}

Barreto (1993) explica que o termo racionalidade refere-se a uma capacidade que se presume ser exclusiva da espécie humana, utilizada para ponderar, julgar, estabelecer relações lógicas e praticar 
bom senso. A raiz do termo racionalidade está na palavra razão, do latim ratione, a qual consiste no raciocínio. Pizza (1994) enfatiza que as origens filosóficas do conceito de razão encontram-se entre os filósofos gregos. Esse conceito foi proposto, segundo o autor, inicialmente por Platão (428-347 a.C.), o qual não fez nenhuma distinção de tipos de razão. Com isso, na visão clássica, a razão é uma só e representa o conceito ordenador da vida. Contudo, na modernidade, com Descartes e Hobbes, o conceito de razão deixa de representar o centro ordenador da existência e se transforma em um instrumento de previsão de consequências. Assim, a preocupação, com o entendimento do mundo, de si próprio e da natureza deixa de ser importante e prioritária para o homem, e torna-se relevante o que é útil, como, por exemplo, a iniciativa dirigida para a acumulação de bens e riquezas ou de dominação econômica.

O conceito de racionalidade, na literatura sociológica clássica, representa o elemento mais importante do pensamento weberiano (Kalberg, 1980). Nele, o autor evidencia que as diferentes formas organizacionais existentes na sociedade podem ser explicadas pela predominância do uso de racionalidades específicas. A diferenciação das racionalidades refere-se aos processos mentais e às referências utilizadas que irão orientar as ações dos indivíduos no contexto social, e pode se apresentar em quatro tipos. Assim, têm-se: (a) racionalidade prática - é própria do modo de vida cotidiano, no qual as atividades do dia a dia são julgadas em relação a interesses individuais, puramente práticos e egoístas; (b) racionalidade teorética - está associada aos processos cognitivos, é também conhecida como racionalidade intelectual, envolve o domínio consciente da realidade pela construção de conceitos abstratos; (c) racionalidade substantiva - direciona a ação orientada por valores emancipatórios (solidariedade, liberdade, comprometimento, etc.), independente dos resultados obtidos; e (d) racionalidade formal - direciona a ação conforme regras, leis e regulamentos institucionalizados com base no cálculo utilitário de consequências no estabelecimento de relações estratégicas entre um meio e um fim. Kalberg (1980) explica que esta última é conhecida também como racionalidade instrumental, e predomina nas chamadas organizações burocráticas. "Weber refere-se à dominação burocrática como formalmente racional porque nela domina a ação orientada para regras e estatutos gerais intelectualmente analisáveis, assim como a seleção dos meios mais adequados para o contínuo seguimento deles" (Kalberg, 1980, p. 1158). As racionalidades instrumental e substantiva representam os dois tipos de racionalidades geralmente investigados nos estudos organizacionais. Assim, elas são, além dos sentidos do trabalho, os objetos de análise neste artigo.

Nas organizações contemporâneas, Cooper e Burrel (1988) e Clegg (1990) enfatizam que tem sido adotada, além de formas mais flexíveis de organização do trabalho, uma lógica de ação diferente da instrumental, típica das chamadas organizações modernas ou do modelo burocrático de organização. Clegg (1990) explica, por meio de uma investigação junto a empresas asiáticas, realizada com base em sete imperativos organizacionais (missão, metas, estratégias e funções principais; relações funcionais; coordenação e controle; responsabilidade e relacionamento de papéis/formação de habilidades; planejamento e comunicação; relação entre desempenho e recompensa; e liderança ${ }^{(4)}$, que existem, nessas organizações, evidências suficientes indicadoras de uma racionalidade diferente da instrumental, ou seja, traços de uma racionalidade substantiva. O autor salienta que, dentre as características dos imperativos analisados, destacam-se as práticas democráticas, o empowerment, a flexibilidade, as técnicas de longo prazo, a confiança na liderança, entre outras.

Entretanto, para Dellagnelo e Machado-da-Silva (2000), tais práticas não representariam necessariamente uma ruptura com o modelo burocrático de organização, caracterizado pela predominância da racionalidade instrumental. Em uma investigação documental realizada em 34 artigos de periódicos nacionais e estrangeiros que continham evidências empíricas de novas formas organizacionais em organizações privadas, industriais e de serviços, os autores buscaram identificar se essas novas formas representariam ruptura com o modelo burocrático de organização. As organizações foram analisadas quanto ao seu potencial de flexibilidade tecnológica, estrutural e cultural, e considerou-se, principalmente, o tipo de racionalidade predominante na ação organizacional. Conforme os autores, a caracterização da organização somente em termos de flexibilidade não seria suficiente para determinar a ruptura com o modelo burocrático. Por meio do estudo, os autores 
inferiram que a dimensão tecnológica apresentou um maior potencial de flexibilidade; já as dimensões estrutural e cultural, potencial médio; e a racionalidade instrumental predominou nas ações organizacionais. Apesar da forte tendência de flexibilização do modelo burocrático no que diz respeito às categorias investigadas, não se verificou uma ruptura. A lógica de ação predominante foi a instrumental, baseada principalmente na preocupação em buscar soluções para adaptar-se a um contexto competitivo por meio da utilização do cálculo utilitário de consequências. Isso ocorre a fim de justificar a utilização de práticas de flexibilização do trabalho com foco no cliente, nas estruturas salariais, na qualificação polivalente.

Nos estudos organizacionais brasileiros sobre racionalidades instrumental e substantiva, destacam-se as pesquisas de Serva (1993, 1996, 1997a, 1997b). O autor desenvolve seus estudos com base nas ideias de A. G. Ramos (1989) sobre a racionalidade, apresentadas como a teoria substantiva da vida humana associada, e de Habermas (1999), sobre a teoria da ação comunicativa. A. G. Ramos (1989) apresenta uma crítica à razão moderna, e visa preparar um caminho para o desenvolvimento de uma nova ciência das organizações. $\mathrm{O}$ autor explica que a racionalidade funcional ou instrumental embasa a teoria corrente da organização, a qual admite como legítima a ilimitada intrusão do sistema de mercado na vida humana. Assim, o autor destaca o papel da razão substantiva, a qual seria um atributo natural do ser humano que reside na psique, como a principal categoria de análise de sua teoria, e a ética como a disciplina preponderante para a estruturação da vida humana. Habermas (1999), por sua vez, elaborou um dos estudos mais significativos da atualidade sobre racionalidade, o qual representa uma proposta de explicação das possibilidades de ação racional na sociedade industrial contemporânea, com vistas à emancipação do homem ante os constrangimentos impostos por essa sociedade. Segundo o autor, a ação pode se apoiar em dois eixos: a orientação para o êxito/ação instrumental ou estratégica; ou a orientação para o entendimento/ação comunicativa. Assim, na ação comunicativa, os participantes não se orientam primariamente para o próprio êxito, mas por atos de entendimento interpessoal. Nela, os atores sociais buscam o consenso sobre planos de ação em uma determinada situação.

Serva (1996, 1997a, 1997b) conceitua a ação racional substantiva como um tipo de ação orientada para a autorrealização, a qual possibilita o alcance da satisfação social e é fundamentada no debate racional e no julgamento ético-valorativo das ações. Os seus elementos constitutivos são a autorrealização, o entendimento, o julgamento ético, a autenticidade, os valores emancipatórios e a autonomia. A ação racional instrumental é definida pelo autor como aquela pautada no cálculo utilitário, no êxito econômico e no poder, e constituída pelos seguintes elementos: cálculo, fins, maximização dos recursos, êxito, resultados, desempenho, utilidade, rentabilidade, e estratégia interpessoal. $\mathrm{O}$ mesmo autor buscou investigar, em organizações produtivas ${ }^{(5)}$, a presença da razão substantiva e instrumental nas práticas organizacionais. Ele relacionou os elementos constitutivos da racionalidade substantiva e instrumental a 11 desses processos. Tais processos são: hierarquia e normas, valores e objetivos, tomada de decisão, controle, divisão do trabalho, comunicação e relações interpessoais, ação social e relações ambientais, reflexão sobre a organização, conflitos, satisfação individual, e dimensão simbólica. O autor explica que, nas práticas das organizações produtivas, estão presentes tanto a razão substantiva quanto a razão instrumental, pois, segundo ele, não há uma organização totalmente regida por uma delas. Foram investigadas três organizações privadas, atuantes no setor de serviços (educação infantil, produção artística, editora, clínica médico-psicológica e de psicoterapia), situadas na cidade de Salvador, e em duas delas predominou a racionalidade substantiva. A pesquisa foi realizada por meio de metodologia qualitativa, observação participante, e desenvolvida no período de abril a dezembro de 1993 (Serva, 1996, 1997a, 1997b).

Contudo, Dellagnelo e Machado-da-Silva (2000), ao analisarem os estudos de Serva (1996, 1997a, 1997b), questionam se as organizações apresentadas pelo autor como substantivas obteriam sucesso com as mesmas práticas administrativas adotadas em condições de mercado mais competitivas, ou seja, se manteriam uma ação racional substantiva. Os autores explicam que a prática da medicina naturalista, de editoras e de escolas com filosofias educacionais alternativas, que foram as organizações investigadas, parece ser coerente com os valores considerados mais substantivos na sociedade. Assim, a adoção de práticas organizacionais convergentes com valores substantivos 
mantém coerência com o perfil dos profissionais que atuam nessas organizações. Contudo, o sucesso empresarial dessas organizações, antes de representar evidência significativa da emergência de modelos organizacionais alternativos ao burocrático, deve ser analisado à luz do padrão de competitividade no segmento de mercado no qual elas estão inseridas.

Pinto (2001) investigou que tipo de racionalidade prevalece na prática administrativa de uma fundação empresarial aberta - fundação A, a qual foi constituída com o objetivo de promover, apoiar, incentivar e patrocinar ações em áreas como educação, cultura, saúde e assistência social. Os dados foram coletados por meio de observação participante e usou-se uma escala de valores organizacionais. O autor utilizou as categorias de análise propostas por Serva (1996) e constatou que, das sete categorias consideradas essenciais, a racionalidade instrumental prevaleceu em cinco delas (hierarquia e normas, valores e objetivos, tomada de decisão, divisão do trabalho, comunicação e relações interpessoais). Segundo o autor, devido às peculiaridades das fundações empresariais (porte, abrangência de atuação, volume de recursos aportados, fiscalização do Ministério Público, influência do instituidor, entre outros), a predominância da racionalidade instrumental torna-se inerente a suas práticas administrativas. No estudo de Valeriano (2006), analisou-se a racionalidade na práxis administrativa da Coopervale - Cooperativa de Consumo dos Empregados do grupo CVRD (Companhia Vale do Rio Doce), localizada na cidade de Itabira/MG. O autor utilizou como principal instrumento de coleta de dados a entrevista semiestruturada e identificou, por meio da investigação de 11 categorias de análise propostas por Serva (1996) - hierarquia e normas, valores e objetivos, tomada de decisão, controle, divisão do trabalho, comunicação e relações interpessoais, ação social e relações ambientais, reflexão sobre a organização, conflitos, satisfação individual e dimensão simbólica -, a presença mediana da racionalidade substantiva na organização investigada.

M. F. Ramos (2006) avaliou a racionalidade por meio de entrevistas semiestruturadas e grupos focais em três organizações do terceiro setor - uma ONG e duas fundações - e buscou avaliar a tensão existente entre as racionalidades instrumental e substantiva e seus reflexos para a avaliação de programas sociais coordenados por essas organizações. Na organização A (ONG), são desenvolvidos programas com foco na formação profissional e na inclusão de jovens em situação de vulnerabilidade social. A organização B (fundação) foi criada por iniciativa de uma empresa que explora e industrializa minério, e seus membros têm como foco desenvolver programas de cidadania ambiental, educação ambiental nas escolas, alfabetização de jovens e adultos, informatização de escolas e outros. Já a organização C (fundação) foi criada por um conglomerado empresarial do setor financeiro, e nela são realizados projetos com foco em ciência e tecnologia, cultura, geração de trabalho e renda, assistência social, saúde e educação. A pesquisa foi realizada com base em cinco categorias de análise (valores e objetivos, tomada de decisão, controle, comunicação, e reflexão sobre a organização), as quais foram adaptadas dos estudos de Serva (1996). M. F. Ramos (2006) concluiu que as organizações pesquisadas vivenciam a tensão entre as racionalidades substantiva e instrumental, e que os traços de cada uma destas apresentam-se de forma e intensidade variadas, e de acordo com especificidades de cada organização. Nas organizações A e B (ONG e fundação), a racionalidade substantiva foi predominante, e são utilizados processos de avaliação com maior grau de inserção dos técnicos junto às comunidades. Essa proximidade resulta numa prática de avaliação que pressupõe o diálogo, a construção de consenso sobre o objeto de avaliação e sobre os resultados esperados. Contudo, a racionalidade instrumental predominou nas práticas de avaliação de programas sociais desenvolvidas pela organização C (fundação). Esta opera com um volume expressivo de recursos, seu instituidor pertence ao setor financeiro e possui traços marcantes de uma organização burocrática, e os técnicos e responsáveis são oriundos da organização instituidora. Conforme o pesquisador, esses fatores podem explicar a forte presença de indicadores que caracterizam uma racionalidade instrumental. $\mathrm{O}$ autor enfatiza ainda que o critério mais determinante da realização de avaliações nessa organização são os custos dos programas, e não as transformações sociais ocasionadas por eles.

$\mathrm{Na}$ investigação realizada por Severo e Pedrozo (2008), buscou-se verificar, por meio de entrevistas semiestruturadas e de questionário fechado, se os produtores de bergamota orgânica cooperados da Cooperativa de Citricultores Ecológicos do Vale do Caí/RS (Ecocitrus), ao decidirem pelo cultivo orgânico, foram orientados mais por uma motivação substantiva ou instrumental. 
Observou-se também se a cooperativa pode ser considerada uma organização substantiva. A pesquisa foi realizada com base em dez categorias de análise (hierarquia e normas, valores e objetivos, tomada de decisão, controle, divisão do trabalho, comunicação e relações interpessoais, ação social e relações ambientais, reflexão sobre a organização, satisfação individual, e dimensão simbólica) propostas por Serva (1997a), e constatou-se a predominância da racionalidade substantiva em sete das dez categorias analisadas.

Constata-se, conforme a análise dos estudos relatados, que há nas organizações a presença de ambas as racionalidades. A dinâmica do cotidiano das organizações produtivas implica na presença tanto da razão substantiva quanto da razão instrumental. Assim, identificar a predominância de uma delas é assumir que ambas as racionalidades podem estar presentes em todos os processos organizacionais, num dado período (Serva, 1996, 1997a, 1997b). Com isso, neste artigo, não se pretende trabalhar com a lógica dicotômica de que os elementos das racionalidades substantiva e instrumental são excludentes.

A análise dos estudos realizados sobre sentidos de trabalho e racionalidade possibilita inferir que existem algumas aproximações entre os elementos que caracterizam os sentidos atribuídos ao trabalho e os traços constitutivos das racionalidades instrumental e substantiva. Assim, avalia-se que podem existir sentidos do trabalho do tipo instrumental e do tipo substantivo, bem como uma presença concomitante dos dois tipos de sentidos atribuídos ao trabalho nas organizações de trabalho.

\section{Sentidos do Trabalho na Perspectiva da Racionalidade}

Os ambientes organizacionais são contextos nos quais os sentidos atribuídos ao trabalho e as racionalidades instrumental e substantiva estão imbricados entre si. Apesar do foco dos estudos sobre sentidos do trabalho em geral dar-se sobre categorias profissionais, ou seja, sem a contextualização de um ambiente organizacional específico, infere-se que há uma imbricação entre os sentidos atribuídos ao trabalho e a racionalidade. Isso ocorre pois eles são elaborados em uma determinada sociedade e em organizações nas quais predominam características de racionalidade. Destaca-se que hoje se vive em uma sociedade capitalista, na qual a relação entre meios e fins e o cálculo utilitário das consequências são altamente valorizados.

Em um estudo desenvolvido por Morin (2001), a autora identificou junto a estudantes de administração e a administradores de Quebec e da França que um trabalho com sentido possibilita a independência - obtida por meio do salário -, a autonomia, o autodesenvolvimento, relacionamentos satisfatórios, aprendizagem e crescimento, e contribui para a sociedade. Aqui é possível verificar alguns traços das racionalidades instrumental e substantiva. Morin et al. $(2003,2007)$ realizaram uma pesquisa no Brasil mediante entrevistas semiestruturadas junto a 15 alunos de um curso de especialização em administração de uma instituição de ensino superior na cidade de São Paulo. As autoras concluíram que, para a amostra investigada, "o trabalho é essencial na vida destas pessoas já que ele garante a sobrevivência. O principal sentido apontado por este grupo é que o trabalho permite a sobrevivência" (Morin et al., 2007, p. 47, grifo nosso). Ribas (2003) evidencia que, quando o trabalho é central para o indivíduo porque representa um meio para sobrevivência, ele se constitui em uma mera função instrumental, uma simples relação estratégica entre um meio e um fim. Assim, verificam-se nos resultados dos estudos das pesquisadoras elementos característicos de uma racionalidade instrumental, o que fomenta a articulação entre sentidos atribuídos ao trabalho e a racionalidade. Por meio dos resultados encontrados no estudo, as autoras também concluíram que um trabalho com sentido, além de garantir a sobrevivência, deve caracterizar-se por uma variedade na natureza das tarefas, possibilitar satisfação pessoal, aprendizagem, autonomia, reconhecimento, desenvolvimento de uma identidade e de relacionamentos interpessoais, bem como contribuir para a sociedade e garantir a segurança. São identificados aqui traços que possibilitam definir um paralelo 
com a presença concomitante de uma racionalidade instrumental e de uma substantiva, respectivamente.

Constata-se ainda que alguns elementos constitutivos da ação racional instrumental e substantiva representam também fatores que caracterizam um trabalho com sentido positivo. Morin $e t$ al. $(2003,2007)$ utilizam o padrão B de concepção do trabalho apresentado pela equipe MOW (1987) para caracterizar um trabalho com sentido positivo. Esse padrão é caracterizado por fatores como sentimento de vinculação, recebe-se dinheiro para realizar o trabalho, faz-se isso para contribuir com a sociedade. Em pesquisa realizada por Oliveira, Piccinini, Fontoura e Schweig (2004), os autores utilizaram a proposta de investigação dos sentidos do trabalho apresentada por Morin et al. (2003) e constaram, por meio da aplicação de entrevistas semiestruturadas, que 28 profissionais-estudantes de pós-graduação lato sensu em Gestão de Pessoas de uma universidade do sul do país possuíam concepções positivas de trabalho. Este era visto "como uma forma de realização, que acrescenta valor a algo, e que contribui para a sociedade, fortalecendo seu sentimento de pertencimento" (Oliveira et al., 2004, p. 6). Os autores salientam que um trabalho com sentido é útil para a organização e para a sociedade, e permite o desenvolvimento, a valorização, o reconhecimento e a autorrealização do indivíduo. Em outro estudo desenvolvido por Oliveira (2004), a partir de uma adaptação da classificação utilizada por Morin et al. (2003), junto a 13 cooperados, 5 profissionais em cargos de coordenação e 5 funcionários administrativos filiados à Uniodonto - Cooperativa Odontológica, a partir de uma adaptação da classificação utilizada por Morin et al. (2003), o autor buscou verificar se os fatores relativos à organização do trabalho influem no sentido que os participantes da pesquisa atribuem a ele. Conforme os entrevistados, a forma de organização do trabalho odontológico na cooperativa contribui para que eles executem um trabalho realizador, que os satisfaz e, consequentemente, tem sentido. Um trabalho com sentido, para os investigados, deve possibilitar retorno material, crescimento profissional, valorização, reconhecimento e autorrealização. Já um trabalho sem sentido é aquele que não traz o retorno esperado, seja financeiro, seja em termos de resultado de seus procedimentos junto aos pacientes. Assim, sugere-se que os traços constitutivos das racionalidades instrumental e substantiva estão imbricados aos elementos que caracterizam os sentidos atribuídos ao trabalho.

Ribeiro (2007) usou como referência para sua pesquisa os resultados de diversos estudos sobre a temática, inclusive a proposta de Morin (2001). A autora desenvolveu a investigação por meio de entrevistas semiestruturadas junto a seis trabalhadores de três organizações não governamentais de Belo Horizonte. Para os participantes do estudo, um trabalho com sentido é prazeroso, útil, contribui para a sociedade e modifica alguma situação. Na investigação de Alberton (2008) sobre os sentidos atribuídos ao trabalho junto a 166 profissionais do ramo publicitário de Porto Alegre, a qual também se fundamentou nos estudos de Morin (2001), utilizaram-se entrevistas semiestruturadas e questionários. $\mathrm{O}$ autor constatou que, para os investigados, um trabalho com sentido possibilita a aplicação da criatividade e inovação, prazer, reconhecimento, pagamento de um salário adequado, aprendizagem e aperfeiçoamento. Ono e Binder (2010) utilizaram a proposta de Morin (2001) e Morin et al. (2003) para identificar os sentidos do trabalho junto a 20 profissionais contratados por projetos em TI na Grande São Paulo. Os autores aplicaram entrevistas semiestruturadas e concluíram que, para os entrevistados, um trabalho com sentido possibilita aprendizado, identificação com a tarefa realizada, utilização das habilidades, remuneração adequada, realização de atividades não rotineiras, satisfação e desafios.

Na Tabela 1 são expostos os elementos que constituem, segundo a proposta desenvolvida neste ensaio teórico, o sentido do trabalho do tipo instrumental e o do tipo substantivo. A apresentação desta Tabela é realizada com a finalidade de sugerir uma relação entre os elementos que caracterizam os sentidos instrumental e substantivo atribuídos ao trabalho. 
Tabela 1

\section{Tipos de Sentidos do Trabalho sob a Perspectiva da Racionalidade}

\begin{tabular}{ll}
\hline \multicolumn{1}{c}{ Sentido instrumental do trabalho } & \multicolumn{1}{c}{ Sentido substantivo do trabalho } \\
\hline$>$ Garante a sobrevivência; & $>$ Possibilita autonomia; \\
$>$ Permite retorno financeiro; & $>$ Permite o desenvolvimento de relacionamentos \\
$>$ Possibilita segurança financeira; & satisfatórios; \\
$>$ Possibilita independência financeira; & $>$ Possibilita satisfação pessoal; \\
$>$ É útil para a empresa; & $>$ Possibilita autorrealização; \\
$>$ Possibilita reconhecimento material e financeiro.. & $>$ Possibilita aprendizagem e desenvolvimento; \\
& $>$ Possibilita sentimento de vinculação; \\
& $>$ Possibilita reconhecimento simbólico; \\
& $>$ Contribui para a sociedade. \\
\hline
\end{tabular}

Nota. Fonte: Elaborado pelas autoras.

Verifica-se, por meio das pesquisas apresentadas, que o sentido atribuído ao trabalho é orientado por razões instrumentais e substantivas, as quais estão presentes conjuntamente nos contextos sociais e organizacionais. Assim, é possível identificar, com base nos estudos sobre sentidos do trabalho e racionalidades instrumental e substantiva, duas concepções de sentidos atribuídos ao trabalho, o sentido instrumental e o sentido substantivo. Essas concepções estão imbricadas entre si, pois, de forma concomitante, um trabalho, para ter sentido, deve garantir a sobrevivência, mas também pressupõe satisfação, autonomia, autorrealização e contribuição para a sociedade.

\section{Algumas Reflexões Finais}

Os estudos sobre racionalidade e sentidos do trabalho representam uma complexa rede de variáveis que configuram a ação dos indivíduos nas organizações. A articulação estabelecida por meio do referencial teórico sobre sentidos do trabalho e racionalidade possibilitou relacionar, em nível exploratório, essas duas categorias de estudo e desenvolver a concepção de sentido do tipo instrumental e sentido do tipo substantivo. Destaca-se que há ainda uma imbricação entre ambos os tipos de sentidos nas organizações de trabalho.

Constata-se nos estudos sobre os sentidos atribuídos ao trabalho (Alberton, 2008; Betiol, 2006; Morin, 1996, 2001; Morin et al., 2003, 2007; Oliveira, 2004; Oliveira et al., 2004; Ono \& Binder, 2010; Ribeiro, 2007) que um trabalho com sentido deve garantir a sobrevivência, além de possibilitar aprendizagem, autonomia, satisfação, autorrealização e de contribuir para a sociedade. Essas características também são constituintes das racionalidades instrumental e substantiva respectivamente. Weber (1994) explica que raramente a ação social orienta-se exclusivamente por um tipo de racionalidade. Com isso, infere-se que ambas estão presentes nas ações humanas, podendo manter entre si uma relação de predominância; e, se consideradas associadas aos sentidos atribuídos ao trabalho, caracterizam sentidos instrumentais e substantivos que estão imbricados entre si. Assim, sugere-se que haja, nas organizações de trabalho, uma presença concomitante de tipos distintos de sentidos atribuídos a este.

O desafio organizacional talvez seja, conforme Morin (1996, p. 281), "revalorizar as funções expressivas do trabalho através de incentivos e recompensando de modo justo os esforços de criatividade, de serviços aos outros e empenho pessoal". Além disso, expandir o conceito de eficácia organizacional, o qual deve implicar, além dos valores econômicos, valores sociais, morais, espirituais ou ecológicos. Com isso, em uma sociedade na qual predomina uma lógica instrumental, como expandir esses valores genuinamente? 
A visão da autora vai ao encontro das considerações de autores como Marcuse (1975), Habermas (1999) e Horkheimer (2002), os quais enfatizam que o sentido da vida, especialmente em relação ao trabalho no mundo capitalista, não deve ser estruturado somente a partir de uma racionalidade funcional. $\mathrm{O}$ ponto de partida deve ser uma ação compartilhada entre os indivíduos, visando ao alcance de um bem comum e à introdução de uma base lúdica e de prazer na relação do homem com a sociedade e com o trabalho. Segundo Brief e Nord (1990, como citado em Morin, 1996), dar ao trabalho o sentido de uma atividade que o indivíduo desempenha para ganhar um salário gera consequências negativas, tanto pessoais quanto institucionais. A restrição do sentido do trabalho à perspectiva econômica cria ou reforça a relação contratual entre o indivíduo e a organização que o emprega, dando maior importância à remuneração do que ao espírito de serviço e de comunidade, especialmente à capacidade de transformação e à intencionalidade que faz do trabalho humano algo completamente singular.

Assim, as autoras deste artigo sugerem que, por existirem algumas aproximações entre os traços que caracterizam os sentidos atribuídos ao trabalho e os elementos constituintes das racionalidades instrumental e substantiva, infere-se haver sentidos do tipo substantivo e sentidos do tipo instrumental atribuídos ao trabalho, e que eles estão imbricados entre si no contexto organizacional.

\section{Artigo recebido em 23.02.2011. Aprovado em 04.01.2012.}

\section{Notas}

\footnotetext{
${ }^{1}$ Equipe de investigação Meaning of Work International Research Team (MOW) sediada no Canadá, que desde a década de 1970 investiga o significado e a centralidade do trabalho em diversos países.

${ }^{2}$ Weber (1994, p. 40) explica que "por 'utilidades' entendemos sempre as probabilidades (reais ou supostas) concretas e particulares de aplicabilidade presente ou futura, consideradas como tais por um ou vários agentes econômicos cuja presumível importância como meios para os fins desse agente (ou desses agentes) orienta suas atividades econômicas".

${ }^{3}$ Para Morin (1996, 2001), existe trabalho sem sentido. Contudo, essa concepção não é compartilhada pela maioria dos teóricos que estudam o fenômeno. Morin et al. (2003 e 2007) explicam que um trabalho sem sentido não possibilita a satisfação pessoal, a autonomia, o crescimento e aprendizagem, o desenvolvimento de uma identidade e de relacionamentos interpessoais, bem como não contribui para a sociedade. Constata-se que essas características assemelham-se a concepções negativas do trabalho apresentadas por MOW (1987) e Ribas (2003).

${ }^{4}$ Esses sete imperativos organizacionais foram desenvolvidos por Blunt (1989 como citado em Clegg, 1990).

${ }^{5}$ O termo organizações produtivas é utilizado por Serva (1996, 1997a, 1997b) para conceituar as organizações privadas investigadas em seus estudos.
}

\section{Referências}

Alberton, D. M. (2008). Os sentidos atribuídos ao trabalho pelos profissionais do ramo publicitário de Porto Alegre (Dissertação de mestrado). Universidade Federal do Rio Grande do Sul, Porto Alegre, RS, Brasil.

Barreto, C. R. (1993, setembro). Sobre a racionalidade humana: conceitos, dimensões e tendências. Anais do Encontro Nacional da Associação Nacional de Pós-Graduação e Pesquisa em Administração, Salvador, BA, Brasil, 17.

Basso, I. S. (1998). Significado e sentido do trabalho docente. Caderno CEDES, 19(44), 19-32. Recuperado de http://www.scielo.br/scielo.php?pid=S010132621998000100003\&script=sci_arttext.doi: 10.1590/S0101-32621998000100003 
Bendassolli, P. F. (2009). Psicologia e trabalho: apropriações e significados. São Paulo: Cengage Learning.

Betiol, M. I. S. (2006, setembro). Análise exploratória sobre os sentidos do trabalho em duas visões: região metropolitana de São Paulo e região Parisiense. Anais do Encontro Nacional da Associação Nacional de Pós-Graduação e Pesquisa em Administração, Salvador, BA, Brasil, 30 .

Borges, L. O. de (1997). Os atributos e a medida do significado do trabalho. Psicologia: teoria e pesquisa, 13(2), 211-220.

Borges, L. O. de (1998). Os pressupostos dos estudos do significado do trabalho na psicologia social: no caminho do existencialismo. Vivência, 12(2), 87-105.

Borges, L. O. de, Tamayo, A., \& Alves, A., Filho. (2005). Significado do trabalho entre os profissionais de saúde. In L. O. de Borges (Org.). Os profissionais de saúde e seu trabalho (pp. 143-197). São Paulo: Casa do Psicólogo.

Clegg, S. (1990). Modern organization: organization studies in the postmodern world. London: Sage Publications.

Cooper, R., \& Burrel, G. (1988). Modernism, postmodernism and organization analysis: an introduction. Organization Studies, 9(1), 91-112. doi: 10.1177/017084068800900112

Dellagnelo, E. H. L., \& Machado-da-Silva, C. L. (2000). Novas formas organizacionais: onde se encontram as evidências empíricas de ruptura com o modelo burocrático de organizações? Organizações \& Sociedade, 7(19), 19-33.

Frankl, V. E. (1991). Em busca de sentido: um psicólogo no campo de concentração. Petrópolis: Editora Vozes.

Habermas, J. (1999). Teoria de la accion comunicativa, I: racionalidad de la acción y racionalización social. Madrid: Grupo Santillana de Ediciones, S.A.

Hackman, J., \& Oldham, G. (1975). Development of job diagnostic survey. Journal of Applied Psychology, 60(2), 159-170. doi: 10.1037/h0076546

Horkheimer, M. (2002). Eclipse da razão. São Paulo: Centauro.

Jahoda, M. (1987). Empleo y desempleo: um análisis sociopsicológico. Madrid: Morata.

Kalberg, S. (1980). Max Weber's types of rationality: comerstones for the analysis of racionalization process in history. American Journal of Socioloy, 85(5), 1145-1179.

Leontiev, A. (1978). O desenvolvimento do psiquismo. Lisboa: Livros Horizonte.

Marcuse, H. (1975). Eros e civilização. Rio de Janeiro: Zahar.

Meaning of work international research team. (1987). The meaning of working. London: Academic Press.

Morin, E. (1996). L'efficacité organisationnelle et lê sens du travail. In T. C. Pauchant (Coord.), La quête du sens au travail: gérer nos organizations pour la santé des personnes, de nos sociétés et de la nature (pp. 257-286). Québec: Éditions de l'organisation.

Morin, E. (2001). Os sentidos do trabalho. Revista de Administração de Empresas, 41(3), 8-19. doi: $10.1590 /$ S0034-75902001000300002 
Morin, E., Tonelli, M. J., \& Pliopas, A. L. V. (2003, setembro). O trabalho e seus sentidos. Anais do Encontro Nacional da Associação Nacional de Pós-Graduação e Pesquisa em Administração, Atibaia, SP, Brasil, 27.

Morin, E., Tonelli, M. J., \& Pliopas, A. L. V. (2007). O trabalho e seus sentidos [Edição Especial]. Psicologia \& Sociedade, 19, 47-56. doi: 10.1590/S0102-71822007000400008

Morse, N. C., \& Weiss, R. (1955). The function and meaning of work and the job. American Sociological Review, 20(2), 191-198.

Oliveira, S. R. (2004). Os sentidos do trabalho para os dentistas filiados à Uniodonto (Dissertação de mestrado). Universidade Federal do Rio Grande do Sul, Porto Alegre, RS, Brasil.

Oliveira, S. R., Piccinini, V. C., Fontoura, D. S., \& Schweig, C. (2004, setembro) Buscando o sentido do trabalho. Anais do Encontro Nacional da Associação Nacional de Pós-Graduação e Pesquisa em Administração, Curitiba, PR, Brasil, 28.

Ono, M., \& Binder, M. P. (2010, setembro). Os sentidos do trabalho: estudo com profissionais de TI que atuam por projetos na grande São Paulo. Anais do Encontro Nacional da Associação Nacional de Pós-Graduação e Pesquisa em Administração, Rio de Janeiro, RJ, Brasil, 34.

Pinto, W. S. de (2001). Análise das práticas administrativas de uma fundação empresarial aberta (Dissertação de mestrado). Fundação Getúlio Vargas, Rio de Janeiro, RJ, Brasil.

Pizza, W., Jr. (1994). Razão substantiva. Revista de Administração Pública, 28(2), 7-14.

Ramos, A. G. (1989). A nova ciência das organizações: uma reconceituação da riqueza das nações. Rio de Janeiro: FGV.

Ramos, M. F. (2006). Racionalidade nas organizações do terceiro setor: tensões e implicações para a avaliação de programas sociais (Dissertação de mestrado). Universidade de Brasília, Brasília, DF, Brasil.

Ribas, J. M. B. (Coord.). (2003). Teoria de las relaciones laborales. Barcelona: Editorial UOC.

Ribeiro, A. M. V. (2007). O sentido do trabalho para trabalhadores de organizações nãogovernamentais (Dissertação de mestrado). Faculdade Novos Horizontes, Belo Horizonte, MG, Brasil.

Ruiz-Quintanilha, S. A., \& Claes, R. (2000). Research programs. In J. A. Katz (Ed.), Databases for the study of entrepreneurship (Vol. 4, pp. 335-391). New York: Elsevier Science.

Serva, M. (1993). O fenômeno das organizações substantivas. Revista de Administração de Empresas, $33(2), 36-43$.

Serva, M. (1996). Racionalidade e organizações: o fenômeno das organizações substantivas (Tese de doutorado). Fundação Getúlio Vargas, São Paulo, SP, Brasil.

Serva, M. (1997b). Abordagem substantiva e ação comunicativa: uma complementaridade proveitosa para a teoria das organizações. Revista de Administração Pública, 31(2), 108-134.

Serva, M. (1997a). A racionalidade substantiva demonstrada na prática administrativa. Revista de Administração de Empresas, 37(2), 18-30. doi: 10.1590/S0034-75901997000200003

Severo, L. S., \& Pedrozo, E. A. (2008). A citricultura orgânica na região do Vale do Caí (RS): racionalidade substantiva ou instrumental. Revista de Administração Mackenzie, 9(2), 58-81. 
Tolfo, S. R., Coutinho, M. C., Almeida, A. R., Baasch, D., \& Cugnier, J. (2011). Sentidos y significados del trabajo: um análisis com base em diferentes perspectivas teóricoepistemológicas em Psicología. Universitas Psychología, 10(1), 175-188.

Tolfo, S. R., \& Piccinini, V. (2007). Sentidos e significados do trabalho: explorando conceitos, variáveis e estudos empíricos brasileiros [Edição Especial]. Psicologia \& Sociedade, 19, 38-46. doi: $10.1590 / \mathrm{S} 0102-71822007000400007$

Valeriano, J. C. S. (2006). Racionalidade nas práticas administrativas de uma cooperativa em Itabira/MG (Dissertação de mestrado). Faculdade de Economia e Administração, Belo Horizonte, MG, Brasil.

Weber, M. (1994). Economia e sociedade: fundamentos da sociologia compreensiva (3a ed.). Brasília: Editora da Universidade de Brasília. 